\title{
Denosumab for Elderly Men with Osteoporosis: A Cost-Effectiveness Analysis from the US Payer Perspective
}

\author{
Stuart Silverman, ${ }^{1}$ Irene Agodoa, ${ }^{2}$ Morgan Kruse, ${ }^{3}$ Anju Parthan, ${ }^{3}$ and Eric Orwoll ${ }^{4}$ \\ ${ }^{1}$ Cedars-Sinai Medical Center, 8700 Beverly Boulevard, Los Angeles, CA 90048, USA \\ ${ }^{2}$ Amgen Inc., One Amgen Center Drive, Thousand Oaks, CA 91320, USA \\ ${ }^{3}$ Optum, 950 Winter Street, Suite 2800, Waltham, MA 02451, USA \\ ${ }^{4}$ Oregon Health \& Science University, 3181 SW Sam Jackson Park Road, Portland, OR 97239, USA
}

Correspondence should be addressed to Stuart Silverman; stuarts@bhillsra.com

Received 3 September 2015; Accepted 3 November 2015

Academic Editor: Salvatore Minisola

Copyright (C) 2015 Stuart Silverman et al. This is an open access article distributed under the Creative Commons Attribution License, which permits unrestricted use, distribution, and reproduction in any medium, provided the original work is properly cited.

Purpose. To evaluate the cost-effectiveness of denosumab versus other osteoporotic treatments in older men with osteoporosis from a US payer perspective. Methods. A lifetime cohort Markov model previously developed for postmenopausal osteoporosis (PMO) was used. Men in the model were 78 years old, with a BMD T-score of -2.12 and a vertebral fracture prevalence of $23 \%$. During each 6-month Markov cycle, patients could have experienced a hip, vertebral or nonhip, nonvertebral (NHNV) osteoporotic fracture, remained in a nonfracture state, remained in a postfracture state, or died. Background fracture risks, mortality rates, persistence rates, health utilities, and medical and drug costs were derived from published sources. Previous PMO studies were used for drug efficacy in reducing fracture risk. Lifetime expected costs and quality-adjusted life-years (QALYs) were estimated for denosumab, generic alendronate, risedronate, ibandronate, teriparatide, and zoledronate. Results. Denosumab had an incremental cost-effectiveness ratio (ICER) of \$16,888 compared to generic alendronate and dominated all other treatments. Results were most sensitive to changes in costs of denosumab and the relative risk of hip fracture. Conclusion. Despite a higher annual treatment cost compared to other medications, denosumab is cost-effective compared to other osteoporotic treatments in older osteoporotic US men.

\section{Introduction}

Worldwide, 1 in 5 men over the age of 50 is likely to have osteoporosis. Although osteoporosis is less common in men than women, $25-30 \%$ of all hip fractures are in men and the risk of mortality after osteoporotic fractures is greater in men than in women. The 10-year probability of major osteoporotic fractures increases with age and is particularly high in patients over 75 years old $[1,2]$. Because of growth in the population of older people, the number of hip fractures is estimated to be 1.1 million in men by 2025 [3]. Osteoporotic fractures are associated with considerable morbidity and enormous health care costs [4]. In 2005, about 595,000 osteoporotic fractures were reported in US men, costing $\$ 4.1$ billion [5].

Bisphosphonates and teriparatide are indicated for use in men with osteoporosis, and denosumab is indicated to increase BMD in men with osteoporosis at high risk for fracture [6]. Although denosumab is tolerable and efficacious in men, evidence suggesting economic value is also important. As the US healthcare system continues to evolve, US payers increasingly demand this type of economic information to support value driven decisions about therapeutic options. Denosumab has been demonstrated to be a costeffective strategy compared to bisphosphonates and strontium ranelate in postmenopausal osteoporotic women in both Sweden and the US, as well in osteoporotic men in Sweden $[7,8]$. Although denosumab was reported to be costeffective in older osteoporotic men in Sweden, it is critical to evaluate the cost-effectiveness of denosumab in the US given the differences in the population characteristics, fracture rates, and healthcare reimbursement environment. Therefore, we evaluated the cost-effectiveness of denosumab in elderly 
TABLE 1: Relative risk of fractures.

\begin{tabular}{|c|c|c|c|c|}
\hline & Hip & Vertebral & NHNV & Source \\
\hline Denosumab & 0.38 & 0.36 & 0.84 & $\begin{array}{l}\text { Boonen et al. } 2011 \text { [9], McClung } \\
\text { et al. } 2012 \text { [10] }\end{array}$ \\
\hline Generic Alendronate & $0.62^{*}$ & 0.62 & $0.82^{*}$ & $\begin{array}{l}\text { NICE Evidence Review } 2008 \text { [11] } \\
\text { Inderjeeth et al. } 2009 \text { [12] }\end{array}$ \\
\hline Zoledronate & 0.82 & 0.34 & 0.73 & Boonen et al. 2010 [13] \\
\hline Risedronate & 0.85 & 0.56 & $0.80^{*}$ & $\begin{array}{l}\text { McClung et al. } 2001 \text { [14] } \\
\text { Inderjeeth et al. } 2009 \text { [12] } \\
\text { NICE Evidence Review } 2008 \text { [11] }\end{array}$ \\
\hline Ibandronate & $1.00^{*}$ & $0.51^{*}$ & $1.00^{*}$ & NICE Evidence Review 2008 [11] \\
\hline Teriparatide & $0.25^{*}$ & $0.35^{*}$ & $0.47^{*}$ & NICE Evidence Review 2008 [11] \\
\hline
\end{tabular}

${ }^{*}$ Where data are unavailable in the PMO elderly, the RRs are assumed to be similar to the overall PMO population.

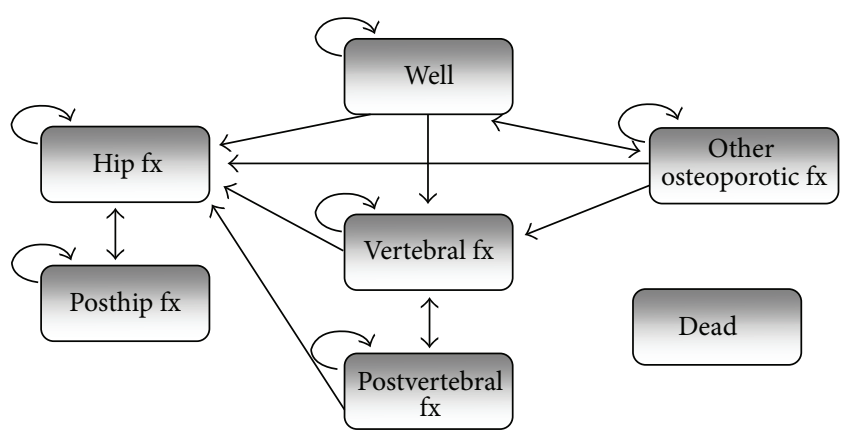

Figure 1: Model structure. Arrows to the health state "dead" are excluded for simplification.

osteoporotic men in the US and compared it to alendronate, risedronate, ibandronate, zoledronate, and teriparatide.

\section{Methods}

A previously published lifetime cohort Markov model was adapted for this analysis; the basic analysis methods and assumptions have been previously described $[7,8,15]$. Since fractures are more common in elderly men, the population of interest was men 75 years and older. The patient characteristics included in the model were reflective of a subgroup analysis of the more elderly participants enrolled in ADAMO (a multicenter, randomized, double-blind, placebo-controlled study to compare the efficacy and safety of denosumab $60 \mathrm{mg}$ every six months versus placebo in males with osteoporosis), with mean age of 78 years, with a femoral neck BMD T-score of -2.12 and prevalent vertebral fractures in $23 \%[16,17]$.

Figure 1 illustrates the health states in the Markov model.

2.1. Treatment Efficacy. Since there is a paucity of wellpowered trials reporting fracture risk reduction in osteoporotic men, data from postmenopausal osteoporosis (PMO) trials were used for the analyses (see Table 1). This approach was used because BMD improvements in response to interventions have consistently been shown to be similar across populations of osteoporotic men and women [16, 18-22]. For instance, in patients on denosumab who were $\geq 75$ years old, the percentage change from baseline to month 12 in lumbar spine BMD was comparable between women in the FREEDOM trial (placebo: 0.7 (95\% CI -0.1-1.4) versus denosumab: 4.8 (95\% CI 4.1-5.6)) and men in the ADAMO trial (placebo: 1.0 (95\% CI -0.5-2.5) versus denosumab: 4.8 (95\% CI 3.36.4)) [16-18]. It is reasonable to assume that similar changes in BMD in men and women will reflect similar effects on fracture risk reduction. This assumption was substantiated in a recent clinical trial in which BMD change and vertebral fracture risk reduction from bisphosphonate therapy in men were similar to parallel studies in women [23]. Moreover, in recognition that therapy-induced fracture risk reduction is likely to be similar in men and women, regulatory agencies routinely approve osteoporosis treatments for fracture reduction in men when BMD improvements in men are similar to those in women [24]. In the absence of evidence for fracture reduction for a particular treatment at a particular skeletal site, $0 \%$ fracture risk reduction was assumed.

2.2. Treatment Duration and Persistence. In the model, patients received treatment up to 5 years except for teriparatide which is only indicated for 2 years of treatment.

The probability of treatment discontinuation within the first three years for the comparators was estimated using persistence data obtained from Weycker et al. and Landfeldt et al. $[25,26]$. Persistence rates were based on a composite estimate of PMO patients taking oral bisphosphonates and then adjusted for men using the Landfeldt et al. data (Supplemental Table 1 in Supplementary Material available online at http://dx.doi.org/10.1155/2015/627631). The persistence rate for denosumab was estimated based on DAPS (Denosumab Adherence Preference Satisfaction) [27], which found patients on denosumab were $50 \%$ less likely to discontinue treatment $(P=0.029)$ than those given alendronate.

The other injectable osteoporosis treatments, teriparatide and zoledronic acid, were assumed to have the same persistence as denosumab (Supplemental Table 1).

2.3. Offset Time. Although antifracture efficacy is likely to persist for a period of time (offset time) after a treatment is stopped, there have been very few studies that report offset time and there is a lack of consensus on the duration of offset time [28-32]. The duration of offset time is likely to 
TABLE 2: Incidence of fractures.

\begin{tabular}{lcccc}
\hline Age & Hip $^{*}$ & NHNV $^{*}$ & $\begin{array}{c}\text { Morphometric } \\
\text { vertebral }^{\dagger}\end{array}$ & $\begin{array}{c}\text { Clinical } \\
\text { vertebral }^{\ddagger}\end{array}$ \\
\hline $75-79$ & 0.0053 & 0.0076 & 0.2 & 0.0045 \\
$80-84$ & 0.0060 & 0.0203 & 0.2 & 0.0045 \\
$85+$ & 0.0150 & 0.0291 & 0.2 & 0.0133 \\
\hline
\end{tabular}

*Source: Melton et al. 1999 [33].

${ }^{\dagger}$ Source: Hasserius et al. 2003 [34]; value shown is prevalence.

${ }^{\ddagger}$ Source: Cooper et al. 1992 [35].

affect the number of incident fractures and mortality, and consequently costs and quality of life. Thus, in the current analyses, offset time was assumed to be equal to up to 2 years across all therapies in the base-case. However, given that some prior models [7] have used offset time up to 5 years for bisphosphonates, a sensitivity analysis was also conducted. In the sensitivity analyses, a 1- or 2-year offset times were applied for denosumab, up to 2.5 years for teriparatide, and up to 5 years for all other comparators.

Furthermore, in the model, it was assumed that offset time could not exceed the treatment duration. For example, if patients on oral bisphosphonates discontinued treatment by year 1 , then their offset time was assumed to be 1 year. On the other hand, if patients on oral bisphosphonates received treatment for a full 5 years, then their offset time was assumed to be 2 years in the base-case and 5 years in the sensitivity analysis. Patients that drop out in the first 6-month Markov cycle did not receive any offset time.

2.4. Incidence of Fractures. The incidence of hip and clinical vertebral and other nonhip, nonvertebral (NHNV) osteoporotic fractures in untreated men were derived from Melton III et al. and Cooper et al. $[33,35]$ and are shown in Table 2 . An explanation of the derivation methodology can be found in a previously published economic analysis [15]. In the absence of age-specific prevalence of morphometric vertebral fracture in the model, a constant risk of morphometric vertebral fracture was assumed when calculating the background population risk [34].

2.5. Mortality. Patients with osteoporotic fractures have a higher mortality compared to the general population [43]. In the model, the age-specific baseline mortality in the US normal population for men in 2010 was applied to the relative risk of mortality after a fracture in Swedish population [44] because US data were not available. It was assumed that mortality in the first year after fracture would be higher than in subsequent years for hip and vertebral fractures. NHNV osteoporotic fractures were assumed to only have an increased risk of mortality in the first year of fracture. The relative risk of mortality in men who have a fracture was estimated from Johnell et al. [43] and applied to the background mortality of the normal population. Relative risks of mortality related to fractures are shown in Supplemental Table 2 (for further methods detail, see Parthan et al.) [15].

2.6. Utility. The effect of hip fracture on quality of life, in the first year and subsequent years, was based on a meta-analysis
[36]. The effect on quality of life from vertebral fracture in the first year was derived from Peasgood et al. [36]. It was assumed that the utility multiplier during the second and following years for a clinical vertebral fracture was 0.93 [37]. The disutility associated with NHNV fractures in the first year was derived from Borgström et al. 2006 [38]. The model assumed that the NHNV fractures did not have any impact on patients' quality of life in the second and subsequent years. The fracture-specific utility multipliers as shown in Table 3 were used together with the baseline utility values for normal US men [45].

2.7. Resource Use and Costs. The model included costs associated with the drug intervention, costs of treating fractures, drug administration, and monitoring costs and long-term care costs (see Table 4). All costs are reported in 2013 USD. Treatment costs including administration and monitoring were not applied for patients who discontinued treatment. Age-specific fracture costs by fracture site were derived from Brenneman et al. and Tosteson et al. [39, 40]. The Tosteson study includes costs for hip fracture patients in both men and women and was used to estimate the costs in the subsequent years following fracture. Costs associated with long-term care were considered in the model because many people with a hip fracture are discharged to a long-term care facility. Since there were no published data on cost of nursing home care in men, the costs were estimated using data from women. Patients with vertebral and NHNV fractures were assumed not to be associated with any long-term costs.

2.8. Analyses. The model was used to estimate both cost and outcomes over a lifetime horizon for each treatment strategy. Total costs included costs of treatment intervention (both drug and administration costs and osteoporosis management costs), direct medical costs for all fracture types, and longterm care costs of a nursing home (as a result of hip fracture). Total QALYs (quality-adjusted life-years) were calculated using the product of the utility weights for each health state and the time spent in that health state and summed for all health states over the patient's lifetime. Total LYs (life-years) were calculated by adding all the time the patients spent in a nondeath health state. Costs and health outcomes were discounted at 3\% annually. Incremental cost-effectiveness ratios (ICERs) were reported as the cost per QALY gained and cost per LY saved. The model also reported the 10-year incidence of all fracture types for each treatment strategy.

As is the standard in health economic methodology, treatment strategies were rank ordered by increasing cost and ICERs were calculated successively for each next most costly strategy. Dominated strategies, those with both higher costs and lower efficacy than a comparator, were removed from the analysis.

2.9. Sensitivity Analyses. Parameters were varied using published confidence intervals or standard errors, where available, and by $25 \%$ above and below their base-case values when not available. The model was rerun while holding all other parameters fixed. Since zoledronate has lost exclusivity, the drug acquisition cost was reduced by $35 \%$ and $65 \%$ of 
TABLE 3: Utility multipliers by fracture type and adverse event.

\begin{tabular}{lcc}
\hline Fracture type/period & Utility multiplier & Source \\
\hline First year after fracture & & Peasgood et al. 2009 [36] \\
Hip fracture & 0.700 & Peasgood et al. 2009 [36] \\
Clinical vertebral fracture & 0.590 & Kanis et al. 2004 [37] \\
NHNV fractures & 0.902 & \\
The second year and following years after fracture & & \\
Hip fracture & 0.800 & Peasgood et al. 2009 [36] \\
Clinical vertebral fracture & 0.930 & Borgström et al. 2006 [38] \\
\hline
\end{tabular}

TABLE 4: Resource use and unit costs.

\begin{tabular}{lccc}
\hline Resource & Cost & Frequency & Source \\
\hline Hip fracture & & & Brenneman et al. 2013 [39] \\
$\quad$ Year 1 & $\$ 28,112$ & - & Tosteson et al. 2008 [40] \\
$\quad$ Year 2+ & $\$ 9,734$ & - & Brenneman et al. 2013 [39] \\
Vertebral fracture & & - & Brenneman et al. 2013 [39] \\
$\quad$ Year 1 & $\$ 9,882$ & - & Brenneman et al. 2013 [39] \\
NHNV fracture & $\$ 236$ & Once every 2 years & Physician's Fee and Coding Guide 2013 [41] \\
Nursing home (per day) & $\$ 243$ & Once per year & Physician's Fee and Coding Guide 2013 [41] \\
BMD measurement & $\$ 100$ & Once per year (zoledronate only) & Physician's Fee and Coding Guide 2013 [41] \\
Physician visit & $\$ 151$ & Twice per year (denosumab only) & Physician's Fee and Coding Guide 2013 [41] \\
Intravenous (IV) injection & $\$ 42$ & - & EncoderPro.com WAC 2013 [42] \\
Nurse visit & $\$ 1,650$ & - & EncoderPro.com WAC 2013 [42] \\
Denosumab (yearly) & $\$ 30$ & - & EncoderPro.com WAC 2013 [42] \\
Generic alendronate (yearly) & $\$ 1,084$ & - & EncoderPro.com WAC 2013 [42] \\
Zoledronate (yearly) & $\$ 1,708$ & - & EncoderPro.com WAC 2013 [42] \\
Risedronate (yearly) & $\$ 1,332$ & - & EncoderPro.com WAC 2013 [42] \\
Ibandronate (yearly) & $\$ 14,514$ & &
\end{tabular}

All costs have been inflated to 2013 USD where necessary.

the current price in sensitivity analyses. As risedronate is expected to lose exclusivity in 2014, a similar analysis was done using the estimated generic price of risedronate.

A probabilistic sensitivity analysis (PSA) was performed to assess uncertainty in the model. The PSA was performed by simultaneously drawing from appropriate distribution functions for each model parameter according to their means and standard errors. This process of drawing parameters and running the model was repeated 1,000 times and the results are presented graphically. The parameters included in the PSA were efficacy of denosumab and the comparators, costs of fractures, utilities, the DAPS ratio, and proportion of patients going to long-term care after hip fracture.

\section{Results}

3.1. Base-Case Results. Results of the multiway costeffectiveness analysis show that generic alendronate had the lowest costs followed by denosumab (Table 5). Compared to generic alendronate, the lifetime costs associated with denosumab were approximately $\$ 900$ higher per patient. However, men on denosumab had 0.05 additional QALYs per patient. This resulted in $\$ 16,900$ per QALY gained. Denosumab had lower costs and higher QALYs per patient than all other comparators, which meant it "dominated" the other comparators.

Compared to all other therapies, patients on denosumab had the lowest 10-year risks of hip fractures in the model (Table 6). Figure 2 displays the disaggregated costs. Across most treatment strategies, costs associated with long-term care accounted for the majority of the lifetime costs. The exception was that drug acquisition costs were the highest in teriparatide patients.

3.2. Sensitivity Analyses. The ICER for denosumab versus generic alendronate is most sensitive to changes in the relative risk of hip fracture with denosumab. When this risk is lowered to 0.18 , denosumab dominates generic alendronate. When this risk is increased to 0.78 , the ICER for denosumab relative to alendronate is $\$ 276,100$ per QALY gained. Other sensitive parameters include the relative risk of hip fracture with alendronate, the drug cost of denosumab, and the unit cost of a day in the nursing home (Figure 3).

Using an estimated generic price for zoledronate and risedronate (assumed to be $35 \%$ and $65 \%$ reductions of the base-case costs, resp.), results did not change; denosumab dominated zoledronate and risedronate. Similarly, results 
TABLE 5: Cost-effectiveness results: base-case.

\begin{tabular}{lcccccccc}
\hline & \multicolumn{3}{c}{ Totals } & \multicolumn{3}{c}{ Incremental } & \multicolumn{2}{c}{ ICERs } \\
& Cost & LYs & QALYs & Cost & LYs & QALYs & Cost per LY saved & Cost per QALY gained \\
\hline Generic alendronate & $\$ 31,456$ & 7.9007 & 5.9866 & - & - & - & Ref. & Ref. \\
Denosumab & $\$ 32,334$ & 7.9339 & 6.0386 & $\$ 878$ & 0.0333 & 0.0520 & $\$ 26,389$ & \$16,888 \\
Zoledronate & $\$ 35,138$ & 7.9132 & 6.0037 & $\$ 2,804$ & -0.0208 & -0.0350 & Dominated & Dominated \\
Risedronate & $\$ 35,232$ & 7.8941 & 5.9760 & $\$ 2,899$ & -0.0399 & -0.0626 & Dominated & Dominated \\
Ibandronate & $\$ 35,550$ & 7.8867 & 5.9663 & $\$ 3,216$ & -0.0472 & -0.0723 & Dominated & Dominated \\
Teriparatide & $\$ 48,828$ & 7.9308 & 6.0279 & $\$ 16,495$ & -0.0031 & -0.0107 & Dominated & Dominated \\
\hline
\end{tabular}

Numbers may not add up due to rounding.

TABLE 6: 10-year risk of events: base-case.

\begin{tabular}{lccc}
\hline & Hip fractures & $\begin{array}{c}\text { Vertebral } \\
\text { fractures }\end{array}$ & $\begin{array}{c}\text { NHNV } \\
\text { fractures }\end{array}$ \\
\hline $\begin{array}{l}\text { Denosumab } \\
\text { Generic }\end{array}$ & 0.138 & 0.101 & 0.232 \\
alendronate & 0.162 & 0.117 & 0.229 \\
Zoledronate & 0.165 & 0.097 & 0.217 \\
Risedronate & 0.170 & 0.115 & 0.227 \\
Ibandronate & 0.176 & 0.113 & 0.235 \\
Teriparatide & 0.147 & 0.112 & 0.216 \\
\hline
\end{tabular}

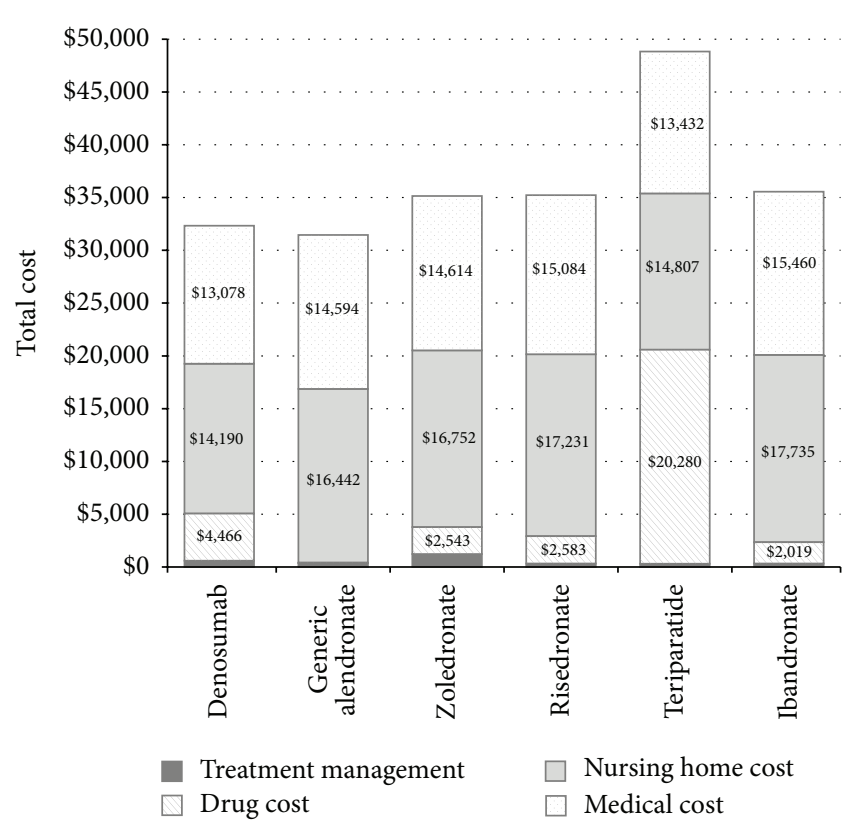

FIGURE 2: Base-case disaggregated costs.

were mostly unchanged when offset times were varied; the ICER for denosumab compared to generic alendronate was $\$ 22,000$ and denosumab dominated all other comparators. In sensitivity analyses, when the offset time for denosumab was reduced from 2 years to one year and all other comparators remained at 2 years, results were similar $($ ICER $=\$ 29,500)$.

The probability of denosumab being cost-effective compared to the other osteoporotic treatment strategies, including generic alendronate, at a threshold of $\$ 100,000$ [46] per
QALY was $85.8 \%$. A cost-effectiveness acceptability curve for the probabilistic sensitivity analyses is illustrated in Figure 4.

\section{Discussion}

In this study, the cost-effectiveness of denosumab compared to other osteoporotic treatments was evaluated in men who were similar to the average elderly patient characteristics in the ADAMO trial. Denosumab had an ICER of $\$ 16,900$ compared to generic alendronate and dominated all other treatment strategies included in the study. Compared to all other treatments, the probability of denosumab being costeffective at a threshold of $\$ 100,000$ [46] per QALY was $85.8 \%$. Results were most sensitive to changes in the relative risk of hip fracture on denosumab, the relative risk of hip fracture with alendronate, the drug cost of denosumab, and the unit cost of a day in the nursing home. The economic benefits of denosumab are probably more pronounced in the elderly population, as hip and vertebral fractures are more common, leading to higher economic costs, morbidity, and mortality [9].

Denosumab was cost-effective using our base-case model. When assumptions and inputs were varied in sensitivity analyses to reflect areas of uncertainty, the results were basically unchanged. This indicates that the simple unit cost of a drug should be only one of several factors used in deciding the most appropriate therapy. Other considerations, such as persistence and efficacy across all fracture types, must be taken into account to recognize the full economic value.

With the exception of the cost-effectiveness study in elderly Swedish men [15], which used the Markov model structure used in the current analysis, we do not know any other published studies that evaluated the cost-effectiveness of different osteoporotic treatments in older men with osteoporosis. In the study of costs in Sweden, denosumab was compared to generic alendronate, generic risedronate, ibandronate, strontium ranelate, zoledronate, and teriparatide. Denosumab dominated all other comparators by having the lowest costs and the greatest QALYs.

This analysis of a cost-effectiveness model based in the US is important despite the previous report in the Swedish context. There are differences in population characteristic, generic availability, and healthcare costs between Sweden and the US that could influence cost-effectiveness estimates and suggest the need for independent analyses. Country-specific 


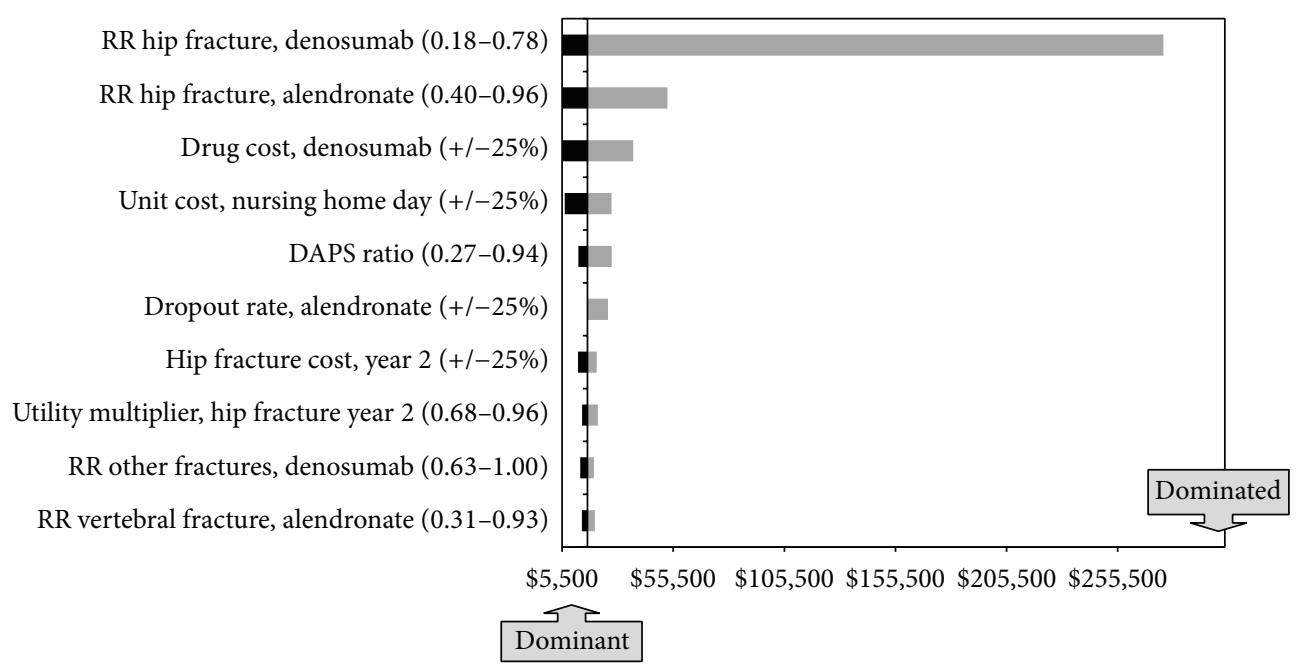

FIgURE 3: Base-case deterministic sensitivity analysis.

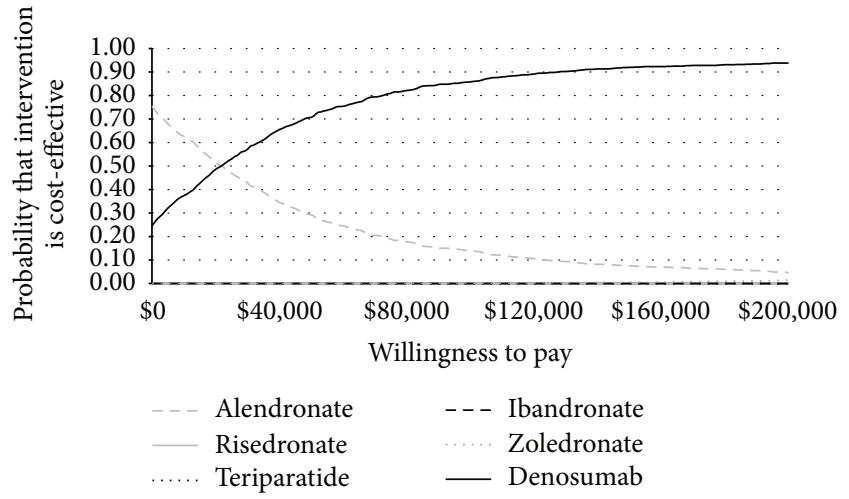

FIgUre 4: Base-case probabilistic sensitivity analysis. Note: CE curves for risedronate, ibandronate, and teriparatide do not appear in the figure, as they are not considered cost-effective at any threshold in this analysis.

data were used for each model and included inputs of background population mortality, background population utility, and background population fracture risk, as well as direct medical costs of fractures, monitoring, and treatments. Persistence data were also country-specific. Due to the availability of data, patients in the US were only at risk of premature discontinuation for the first 3 years while Swedish patients were at risk for 4 years. Despite those differences, findings from the current study and the previous Swedish study are similar; in both, denosumab was a cost-effective treatment in older osteoporotic men. While the population fracture risk, treatment options, and discontinuation patterns differ across countries, denosumab is still the most effective treatment. These findings could potentially be extrapolated to other geographic settings as well.

The assumptions made in the model structure and model inputs are important. The cohort Markov model assumes a hierarchical structure; that is, once patients have experienced a fracture, they cannot have another milder fracture type.
Patients from the posthip fracture state can either sustain another hip fracture, but they cannot experience a vertebral fracture or a NHNV osteoporotic fracture. Patients with vertebral fractures can only incur new vertebral fractures or hip fractures, but not NHNV osteoporotic fractures. Because of this hierarchical structure, the number of milder fractures in the cohort is likely to be slightly underestimated. The model also assumed that patients with vertebral and NHNV osteoporotic fractures do not incur costs beyond the first year of fracture; this may slightly underestimate fracture costs. The relative risks reported for nonvertebral fractures, which may include hip as well as NHNV fractures, were applied for NHNV fractures; this might slightly overestimate the number of NHNV fractures.

Published data concerning the rate of drug-specific discontinuation was only available for the first 3 years of treatment. In the current analysis (except for teriparatide), patients remaining on therapy after 3 years were assumed to continue until planned termination at 5 years. This assumption is supported by long-term studies of discontinuation rates of osteoporosis medications (considered as a group) indicating they are the highest shortly after the initiation of treatment, after which these rates remain stable for 5 or more years $[47,48]$. Discontinuation rates for oral medications were taken from a registry study, but registry data were not available for injectable medications. Therefore, the model used a hazard ratio from the DAPS study [27] to calculate the discontinuation of denosumab and other injectable treatments. Using this methodology, our model predicts $73.6 \%$ of patients are persistent with denosumab at one year. This is consistent with two recent denosumab studies, one prospective and one retrospective, which found $82 \%$ persistence at one year and $70 \%$ persistence at eight months, respectively. Teriparatide is a daily injection, while denosumab and zoledronic acid are 6-month and annual injections, respectively. However, data reported by Landfeldt et al. [25] shows that 1year persistence rates between denosumab and teriparatide are similar. Due to lack of additional data, we assumed the persistence rate for teriparatide to be equal to denosumab at 
2 years as well. Although patients are likely to discontinue teriparatide treatment after 18 months, it is more conservative to assume persistence equal to denosumab at 2 years. Also, in applying the same HR to real-world data for all injectable treatments (denosumab, teriparatide, and zoledronic acid), the model minimizes the potential bias.

This analysis has several potential limitations. First, to most accurately model the effects of denosumab in men, the model's target population was reflective of the elderly men in the ADAMO trial, but it may not represent all male osteoporotic patients. Second, in the real-world setting, patients may receive sequential treatments such as receiving alendronate after discontinuing teriparatide. However, the current model does not take into account pretreated patients or sequential treatments. Nevertheless, the model structure used in the analyses has been widely used in osteoporosis cost-effectiveness research (Jönsson et al. 2011 [7], Borgström et al. 2006 [38], and Kanis et al. 2008 [49]). Only one study by Liu et al. 2006 [50], examined sequential treatment (using teriparatide followed by alendronate) and assumed that the reduction in the risk of fracture was equal to a patient that had not been pretreated. Third, it was assumed here that generic and branded alendronate would have comparable efficacy and safety data. However, Kanis et al. suggest evidence that generic alendronate may be less well tolerated than the branded alendronate. This may affect adherence poorly and thus lead to poorer fracture outcomes, which could impact the cost-effectiveness results [51]. Finally, in the absence of adequate efficacy data in treatment trials in osteoporotic men, fracture reduction rates for the base-case model were derived from studies of PMO. We believe this is reasonable because there is little theoretical reason to suspect treatments will have different effects in men and women, BMD improvements have been shown to be similar across trials in men and women, and the fracture reduction data that are available (e.g., Boonen et al. [23]) indicate similar effects regardless of sex.

The results from this economic analysis suggest that denosumab is a cost-effective option compared to other existing treatments for older osteoporotic men in the US. Even though alendronate is a low cost generic therapy, using a threshold of $\$ 100,000$ per QALY, denosumab was costeffective compared to generic alendronate. When the prices of zoledronate and risedronate were reduced by $35 \%$ and $65 \%$, denosumab was still dominant. The differences in fracture risk reduction and improved persistence with denosumab are the largest drivers for denosumab being cost-effective compared to the other strategies. This analysis illustrates that the selection of treatment for men with osteoporosis should consider factors in addition to simple per dose costs. The significance of selecting the most appropriate osteoporosis treatment may be especially important for planning the overall costs per patient to a health care system payer.

\section{Conflict of Interests}

Irene Agodoa is an employee and shareholder at Amgen Inc. Stuart Silverman and Eric Orwoll received consulting fees and research support from Amgen Inc. Morgan Kruse and Anju Parthan are employees of Optum, which received consulting fees from Amgen Inc.

\section{Acknowledgment}

Funding for this study was provided by Amgen, Inc.

\section{References}

[1] J. A. Kanis, O. Johnell, A. Oden, A. Dawson, C. De Laet, and B. Jonsson, "Ten year probabilities of osteoporotic fractures according to BMD and diagnostic thresholds," Osteoporosis International, vol. 12, no. 12, pp. 989-995, 2001.

[2] O. Ström, F. Borgström, J. A. Kanis et al., “Osteoporosis: burden, health care provision and opportunities in the EU: a report prepared in collaboration with the International Osteoporosis Foundation (IOF) and the European Federation of Pharmaceutical Industry Associations (EFPIA)," Archives of Osteoporosis, vol. 6, no. 1-2, pp. 59-155, 2011.

[3] E. Orwoll, M. Ettinger, S. Weiss et al., "Alendronate for the treatment of osteoporosis in men," The New England Journal of Medicine, vol. 343, no. 9, pp. 604-610, 2000.

[4] J. D. Ringe, P. Farahmand, H. Faber, and A. Dorst, "Sustained efficacy of risedronate in men with primary and secondary osteoporosis: results of a 2-year study," Rheumatology International, vol. 29, no. 3, pp. 311-315, 2009.

[5] R. Burge, B. Dawson-Hughes, D. H. Solomon, J. B. Wong, A. King, and A. Tosteson, "Incidence and economic burden of osteoporosis-related fractures in the United States, 2005-2025," Journal of Bone and Mineral Research, vol. 22, no. 3, pp. 465-475, 2007.

[6] Prolia Prescribing Information, http://pi.amgen.com/united states/prolia/prolia_pi.pdf.

[7] B. Jönsson, O. Ström, J. A. Eisman et al., "Cost-effectiveness of Denosumab for the treatment of postmenopausal osteoporosis," Osteoporosis International, vol. 22, no. 3, pp. 967-982, 2011.

[8] A. Parthan, M. M. Deflin, N. Yurgin, J. Huang, and D. C. Taylor, "Cost-effectiveness of denosumab versus oral bisphosphonates in the United States for Post-Menopausal Osteoporosis (PMO)," Value in Health, vol. 15, no. 4, article A38, 2012.

[9] S. Boonen, J. D. Adachi, Z. Man et al., "Treatment with denosumab reduces the incidence of new vertebral and hip fractures in postmenopausal women at high risk," Journal of Clinical Endocrinology and Metabolism, vol. 96, no. 6, pp. 17271736, 2011.

[10] M. R. McClung, S. Boonen, O. Törring et al., "Effect of denosumab treatment on the risk of fractures in subgroups of women with postmenopausal osteoporosis," Journal of Bone and Mineral Research, vol. 27, no. 1, pp. 211-218, 2012.

[11] National Institute for Health and Clinical Excellence (UK), Systematic Reviews of Clinical Effectiveness Prepared for the Guideline "Osteoporosis: Assessment of Fracture Risk and the Prevention of Osteoporotic Fractures in Individuals at High Risk", National Collaborating Centre for Nursing and Supportive Care, 2008, http://www.nice.org.uk/guidance?action=download $\&$ o $=42362$.

[12] C. A. Inderjeeth, A. C. H. Foo, M. M. Y. Lai, and P. Glendenning, "Efficacy and safety of pharmacological agents in managing osteoporosis in the old old: review of the evidence," Bone, vol. 44 , no. 5, pp. 744-751, 2009. 
[13] S. Boonen, D. M. Black, C. S. Colón-Emeric et al., "Efficacy and safety of a once-yearly intravenous zoledronic acid 5 $\mathrm{mg}$ for fracture prevention in elderly postmenopausal women with osteoporosis aged 75 and older," Journal of the American Geriatrics Society, vol. 58, no. 2, pp. 292-299, 2010.

[14] M. R. McClung, P. Geusens, P. D. Miller et al., "Effect of risedronate on the risk of hip fracture in elderly women," The New England Journal of Medicine, vol. 344, no. 5, pp. 333-340, 2001.

[15] A. Parthan, M. Kruse, I. Agodoa, S. Silverman, and E. Orwoll, "Denosumab: a cost-effective alternative for older men with osteoporosis from a Swedish payer perspective," Bone, vol. 59, pp. 105-113, 2014.

[16] E. Orwoll, C. S. Teglbjærg, B. L. Langdahl et al., "A randomized, placebo-controlled study of the effects of denosumab for the treatment of men with low bone mineral density," Journal of Clinical Endocrinology and Metabolism, vol. 97, no. 9, pp. 31613169, 2012.

[17] ADAMO trial data. Data on file-Amgen, Internal data.

[18] S. R. Cummings, J. S. Martin, M. R. McClung et al., "Denosumab for prevention of fractures in postmenopausal women with osteoporosis," The New England Journal of Medicine, vol. 361, no. 8, pp. 756-765, 2009.

[19] E. S. Orwoll, N. C. Binkley, E. M. Lewiecki, U. Gruntmanis, M. A. Fries, and G. Dasic, "Efficacy and safety of monthly ibandronate in men with low bone density," Bone, vol. 46, no. 4, pp. 970-976, 2010.

[20] J.-M. Kaufman, M. Audran, G. Bianchi et al., "Efficacy and safety of strontium ranelate in the treatment of male osteoporosis," Osteoporosis International, vol. 23, supplement 2, pp. S85386, 2012.

[21] Actonel (risedronate sodium) Prescribing Information, http:// pi.actavis.com/data_stream.asp?product_group $=1874 \& \mathrm{p}=\mathrm{pi} \&$ language $=\mathrm{E}$.

[22] T. Majima, A. Shimatsu, Y. Komatsu et al., "Efficacy of risedronate in Japanese male patients with primary osteoporosis," Internal Medicine, vol. 47, no. 8, pp. 717-723, 2008.

[23] S. Boonen, J.-Y. Reginster, J.-M. Kaufman et al., "Fracture risk and zoledronic acid therapy in men with osteoporosis," The New England Journal of Medicine, vol. 367, no. 18, pp. 1714-1723, 2012.

[24] EMEA and Committee for Medicinal Products for Human Use, Guideline on the Evaluation of Medicinal Products in the Treatmentof Primary Osteoporosis, EMEA, 2006.

[25] E. Landfeldt, O. Ström, S. Robbins, and F. Borgström, "Adherence to treatment of primary osteoporosis and its association to fractures-the Swedish Adherence Register Analysis (SARA)," Osteoporosis International, vol. 23, no. 2, pp. 433-443, 2012.

[26] D. Weycker, D. Macarios, J. Edelsberg, and G. Oster, "Compliance with drug therapy for postmenopausal osteoporosis," Osteoporosis International, vol. 17, no. 11, pp. 1645-1652, 2006.

[27] N. Freemantle, S. Satram-Hoang, E.-T. Tang et al., "Final results of the DAPS (denosumab adherence preference satisfaction) study: a 24-month, randomized, crossover comparison with alendronate in postmenopausal women," Osteoporosis International, vol. 23, no. 1, pp. 317-326, 2012.

[28] B. Jönsson, C. Christiansen, O. Johnell, J. Hedbrandt, and G. Karlsson, "Cost-effectiveness of fracture prevention in established osteoporosis," Scandinavian Journal of Rheumatology, vol. 25, no. 103, pp. 30-38, 1996.

[29] NICE, "Osteoporosis-secondary prevention including strontium ranelate: appraisal consultation document," 2008, http:// www.nice.org.uk.
[30] O. Johnell, B. Jönsson, L. Jönsson, and D. Black, "Cost effectiveness of alendronate (fosamax) for the treatment of osteoporosis and prevention of fractures," PharmacoEconomics, vol. 21, no. 5, pp. 305-314, 2003.

[31] D. M. Black, A. V. Schwartz, K. E. Ensrud et al., "Effects of continuing or stopping alendronate after 5 years of treatment: the Fracture Intervention Trial long-term extension (FLEX): a randomized trial," The Journal of the American Medical Association, vol. 296, no. 24, pp. 2927-2938, 2006.

[32] Y. Z. Bagger, L. B. Tankó, P. Alexandersen, P. Ravn, and C. Christiansen, "Alendronate has a residual effect on bone mass in postmenopausal Danish women up to 7 years after treatment withdrawal," Bone, vol. 33, no. 3, pp. 301-307, 2003.

[33] L. J. Melton III, C. S. Crowson, and W. M. O’Fallon, “Fracture incidence in Olmsted County, Minnesota: comparison of urban with rural rates and changes in urban rates over time," Osteoporosis International, vol. 9, no. 1, pp. 29-37, 1999.

[34] R. Hasserius, M. K. Karlsson, B. E. Nilsson, I. RedlundJohnell, and O. Johnell, "Prevalent vertebral deformities predict increased mortality and increased fracture rate in both men and women: a 10-year population-based study of 598 individuals from the Swedish cohort in the European Vertebral Osteoporosis Study," Osteoporosis International, vol. 14, no. 1, pp. 61-68, 2003.

[35] C. Cooper, E. J. Atkinson, W. M. O’Fallon, and L. J. Melton III, "Incidence of clinically diagnosed vertebral fractures: a population-based study in Rochester, Minnesota, 1985-1989," Journal of Bone and Mineral Research, vol. 7, no. 2, pp. 221-227, 1992.

[36] T. Peasgood, K. Herrmann, J. A. Kanis, and J. E. Brazier, "An updated systematic review of health state utility values for osteoporosis related conditions," Osteoporosis International, vol. 20, no. 6, pp. 853-868, 2009.

[37] J. A. Kanis, O. Johnell, A. Oden et al., "The risk and burden of vertebral fractures in Sweden," Osteoporosis International, vol. 15, no. 1, pp. 20-26, 2004.

[38] F. Borgström, B. Jönsson, O. Ström, and J. A. Kanis, "An economic evaluation of strontium ranelate in the treatment of osteoporosis in a Swedish setting: based on the results of the SOTI and TROPOS trials," Osteoporosis International, vol. 17, no. 12, pp. 1781-1793, 2006.

[39] S. K. Brenneman, N. Yurgin, and Y. Fan, "Cost and management of males with closed fractures," Osteoporosis International, vol. 24, no. 3, pp. 825-833, 2013.

[40] A. N. A. Tosteson, L. J. Melton III, B. Dawson-Hughes et al., "Cost-effective osteoporosis treatment thresholds: the United States perspective," Osteoporosis International, vol. 19, no. 4, pp. 437-447, 2008.

[41] Physician's Fee and Coding Guide 2013, MAG Mutual Healthcare Solutions, 2012.

[42] WAC 2013, http://www.encoderpro.com/.

[43] O. Johnell, J. A. Kanis, A. Odén et al., "Mortality after osteoporotic fractures," Osteoporosis International, vol. 15, no. 1, pp. 38-42, 2004.

[44] Swedish Life Tables 2010, http://www.mortality.org/.

[45] J. Hanmer, W. F. Lawrence, J. P. Anderson, R. M. Kaplan, and D. G. Fryback, "Report of nationally representative values for the noninstitutionalized US adult population for 7 health-related quality-of-life scores," Medical Decision Making, vol. 26, no. 4, pp. 391-400, 2006. 
[46] J. E. Siegel, G. W. Torrance, L. B. Russell, B. R. Luce, M. C. Weinstein, and M. R. Gold, "Guidelines for pharmacoeconomic studies. Recommendations from the panel on cost effectiveness in health and medicine," PharmacoEconomics, vol. 11, no. 2, pp. 159-168, 1997.

[47] K. F. Huybrechts, K. J. Ishak, and J. J. Caro, "Assessment of compliance with osteoporosis treatment and its consequences in a managed care population," Bone, vol. 38, no. 6, pp. 922-928, 2006.

[48] D. H. Solomon, J. Avorn, J. N. Katz et al., "Compliance with osteoporosis medications," Archives of Internal Medicine, vol. 165, no. 20, pp. 2414-2419, 2005.

[49] J. A. Kanis, J. Adams, F. Borgström et al., "The cost-effectiveness of alendronate in the management of osteoporosis," Bone, vol. 42, no. 1, pp. 4-15, 2008.

[50] H. Liu, K. Michaud, S. Nayak, D. B. Karpf, D. K. Owens, and A. M. Garber, "The cost-effectiveness of therapy with teriparatide and alendronate in women with severe osteoporosis," Archives of Internal Medicine, vol. 166, no. 11, pp. 1209-1217, 2006.

[51] J. A. Kanis, J.-Y. Reginster, J.-M. Kaufman et al., "A reappraisal of generic bisphosphonates in osteoporosis," Osteoporosis International, vol. 23, no. 1, pp. 213-221, 2012. 


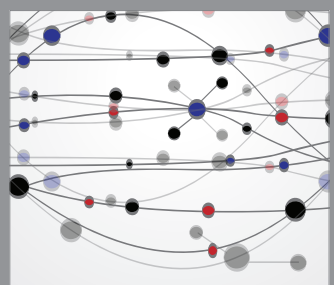

The Scientific World Journal
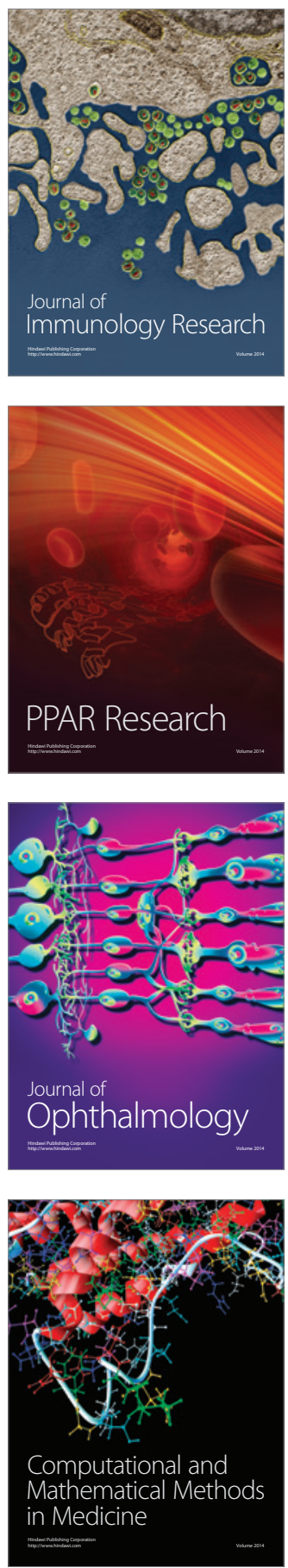

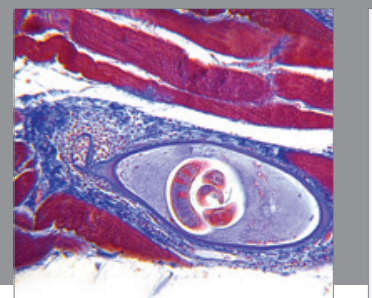

Gastroenterology

Research and Practice
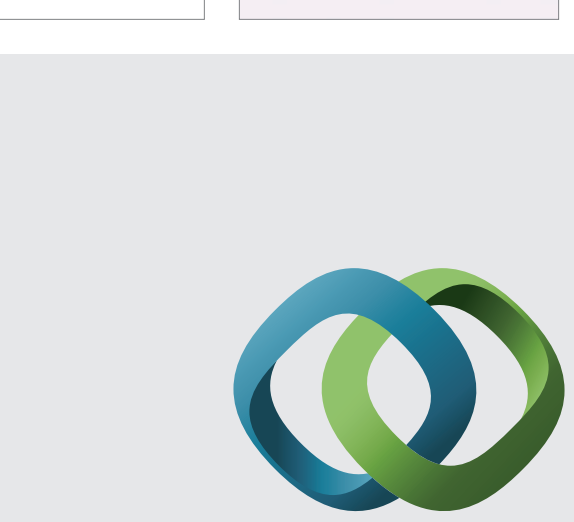

\section{Hindawi}

Submit your manuscripts at

http://www.hindawi.com
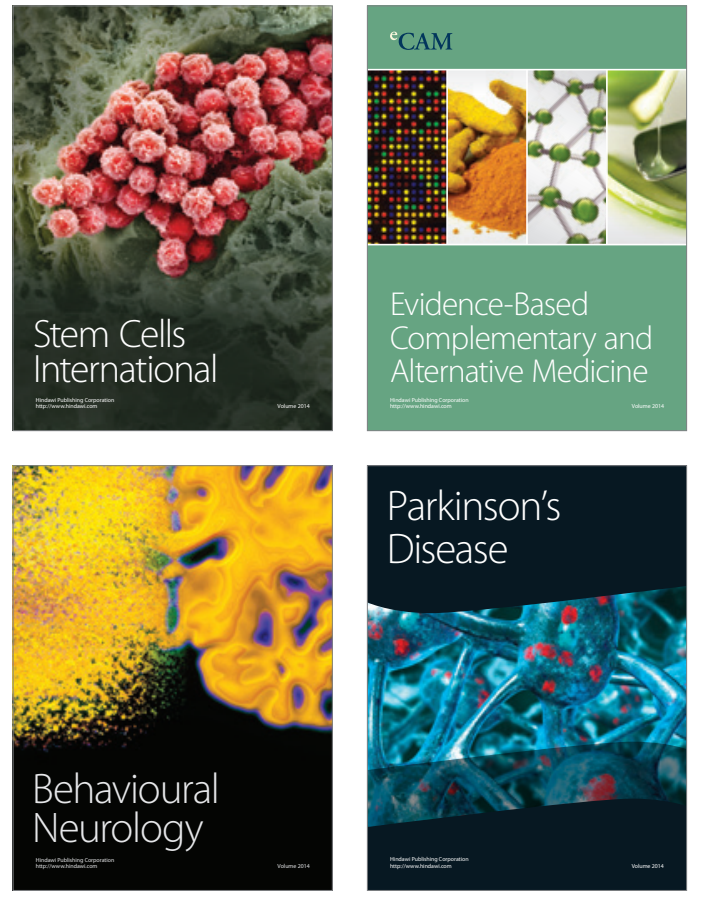
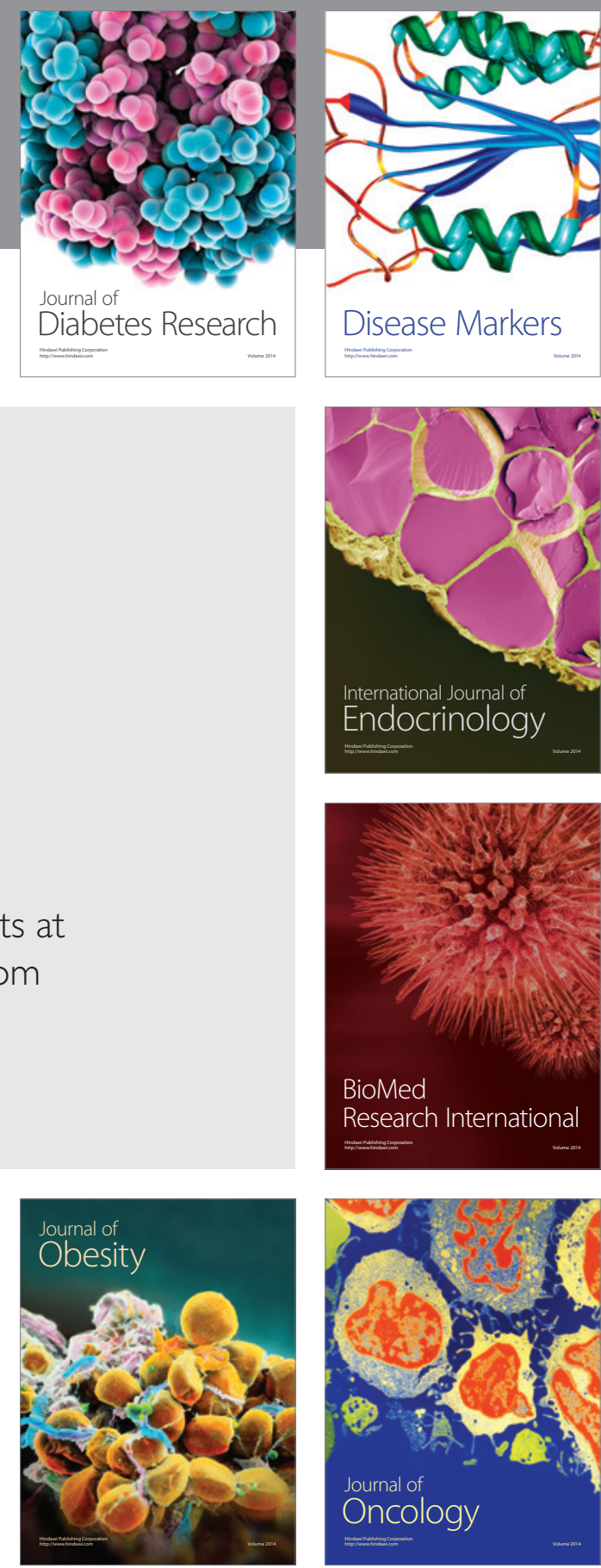

Disease Markers
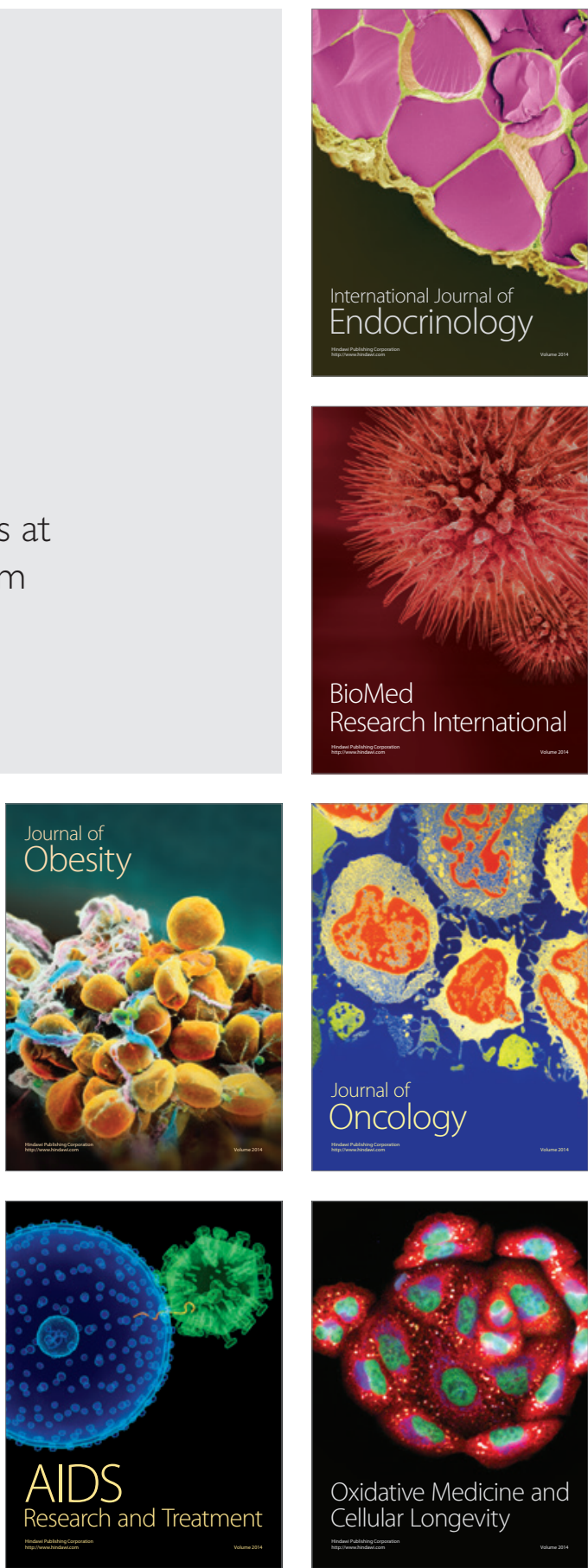